GegGebra

\title{
O GeoGebra no estudo das funções trigonométricas: uma experiência em um minicurso com alunos do $2^{\circ}$ ano do Ensino Médio
}

\author{
GeoGebra in the study of trigonometric functions: an experiment in a course \\ with students of the $2^{\text {nd }}$ year of high school
}

\author{
LÚCIA HELENA COSTA BRAZ ${ }^{1}$ \\ GUSTAVO TEIXEIRA DE CASTRO ${ }^{2}$ \\ PATRICK MACÊDO OLIVEIRA ${ }^{3}$
}

http://dx.doi.org/10.23925/2237-9657.2019.v8i1p071-085

\begin{abstract}
RESUMO
O presente trabalho tem o objetivo de apresentar resultados de uma experiência com o uso de tecnologias no ensino de Matemática na Educação Básica. A partir da literatura consultada, considera-se que a utilização das tecnologias na sala de aula tende a fazer com que os alunos assumam um papel ativo no processo de construção do conhecimento. Buscando ilustrar seu uso e vantagens, além de propiciar a experiência docente enquanto ainda licenciandos, foram planejadas e desenvolvidas atividades com alunos do $2^{\circ}$ ano do Ensino Médio de uma escola pública da cidade de Formiga (MG), com uma abordagem didática baseada na investigação matemática e fazendo uso do software GeoGebra, cujo objetivo principal era introduzir o estudo das funções trigonométricas seno, cosseno e tangente. Os resultados mostraram que a utilização do GeoGebra com uma abordagem baseada na investigação matemática contribuiu significativamente para a compreensão dos conteúdos envolvidos e para que os alunos pudessem assumir um papel ativo no processo de construção do conhecimento. Enquanto formadora de professores e futuros docentes, a experiência foi enriquecedora para a formação.
\end{abstract}

Palavras-chave: Trigonometria; GeoGebra; investigação matemática.

\begin{abstract}
The present work has the objective of presenting results of an experience with the use of technologies in the teaching of Mathematics in Basic Education. From the literature consulted, it is considered that the use of technologies in the classroom tends to make the students take an active role in the process of knowledge construction. In order to illustrate its use and advantages, in addition to providing the teaching experience while still graduating, activities were planned and developed with students of the 2nd year of High School of a public school in the city of Formiga (MG), with a didactic approach based on mathematical research and making use of GeoGebra software, whose main objective was to introduce the study of sine, cosine and tangent trigonometric functions. The results showed that the use of GeoGebra with an approach based on mathematical research contributed significantly to the understanding of the contents involved and so
\end{abstract}

\footnotetext{
1 Instituto Federal de Educação Ciência e Tecnologia de Minas Gerais - Campus Formiga - lucia.helena@ifmg.edu.br

2 Escola Estadual Professor Joaquim Rodarte - gustavo.teixeira@ufv.br

3 Instituto Federal Minas Gerais, Campus Formiga - patrick16moliveira@gmail.com
} 
that students could take an active role in the process of knowledge construction. As a teacher trainer and future teacher, the experience was enriching for the training.

Key-words: Trigonometry; GeoGebra; mathematical investigation.

\section{Introdução}

As dificuldades para ensinar Matemática no Brasil e em outros países vêm fazendo que os pesquisadores em Educação Matemática, no intuito de diminuir a relação dicotômica entre o que é ensinado e o que de fato é aprendido pelos alunos, busquem cada vez mais metodologias e estratégias de ensino. E é nesse cenário que surgem as tecnologias no ensino e na aprendizagem da Matemática como estratégia de ensino-aprendizado. Diversos são os recursos tecnológicos presentes no cotidiano das pessoas e, então, cabe a pergunta: como incorporar esses recursos ao trabalho de sala de aula? (CARGNIN; FRIZZARINI, 2018).

No caso das tecnologias, D’Ambrósio (1993, p.38) aponta que:

[...] dificilmente um professor de Matemática formado em um programa tradicional, com concepções de Matemática pronta e acabada, está preparado para enfrentar os desafios das modernas propostas curriculares. As pesquisas sobre a ação do professor mostram que em geral o professor ensina da forma como lhe foi ensinado.

Nesse sentido, órgãos governamentais, como o Conselho Nacional de Educação (CNE), "vêm implantando políticas educacionais na busca de contemplar elementos considerados indispensáveis na formação de professores que, em sua forma tradicional de organização dos currículos, não são mais consideradas características essenciais para a atuação do professor" (CARGNIN; FRIZZARINI, 2018, p. 20). As autoras destacam o parecer CNE/CES 1.302/2001 que aponta que o licenciando deve adquirir familiaridade com o uso do computador como ferramenta de trabalho, desde o início do curso, incentivando, desta forma, seu uso para o ensino de Matemática.

Pensando nessa possibilidade de o futuro docente ter a experiência de trabalhar em sala de aula com uso de tecnologia enquanto ainda licenciando, a supervisora do Subprojeto Matemática do Programa Institucional de Bolsas de Iniciação à Docência (PIBID) no Instituto Federal de Minas Gerais (IFMG) campus Formiga sugeriu que os bolsistas, alunos do curso de Licenciatura em Matemática, planejassem e desenvolvessem um minicurso durante os Cursos de Verão que a instituição oferece. A proposta foi aceita e dois bolsistas, orientados pela supervisora do Programa, optaram por uma atividade que fizesse o uso do software GeoGebra no estudo das funções trigonométricas.

A escolha do tema a ser investigado, funções trigonométricas, se justifica por este ser apontado como de grande dificuldade de compreensão por parte dos alunos do Ensino Médio (DIONÍZIO; BRANDT, 2011) e a escolha do software GeoGebra, por este ser apontado na literatura como grande facilitador no estudo das funções: "A grande vantagem didática deste programa é que ele apresenta, ao mesmo tempo e no mesmo ambiente visual, representações geométricas e algébricas de um mesmo objeto que interagem entre si” (MAGARINUS, 2013, p. 43). 
O objetivo deste trabalho é, a partir da literatura sobre o uso de tecnologias no ensino de Matemática, relatar e refletir sobre uma experiência com o uso do software GeoGebra, ao utilizá-lo em um minicurso ofertado para alunos do $2^{\circ}$ ano do Ensino Médio de uma instituição pública da cidade de Formiga (MG). O objetivo principal das atividades era introduzir o estudo das funções trigonométricas seno, cosseno e tangente e algumas propriedades, com uma abordagem didática baseada na investigação matemática e fazendo uso do software GeoGebra.

\section{O uso das tecnologias na sala de aula}

Uma das características mais marcantes de nossa sociedade atualmente é, sem dúvida alguma, a velocidade com que surgem tecnologias cada vez mais inovadoras (BORBA; SILVA; GADANIDIS, 2016). Segundo Lopes (2013), a influência dessas tecnologias vem mudando a forma como obtemos informações, ocorrendo também transformações no seu uso na sala de aula. A autora destaca que incluir os recursos da informática como parte das atividades em sala de aula cria possibilidades para que o aluno realize descobertas por si só, incentivando a compreensão e dando significado a conceitos matemáticos.

[...] quando a informática faz parte do ambiente escolar, num processo dinâmico de interação entre alunos, professores e TIC [Tecnologias de Informação e Comunicação], ela passa a despertar no professor a sensibilidade para as diferentes possibilidades de representação da Matemática, o que é importante no momento de realizar construções, análises, observações de regularidades e, também, ao estabelecer relações. (LOPES, 2013, p. 633-634)

Fazer o uso das tecnologias como ferramenta de ensino garante também um ganho no tempo das construções gráficas, na autonomia do aluno e uma melhoria na relação professor-aluno. Softwares que permitem a visualização de gráficos de funções estão sendo muito usados ao longo dos anos, esses novos meios de se trabalhar a matemática permitem que o aluno faça experiências, gere conjecturas e debata, do mesmo modo que em aulas práticas de Biologia ou Física, apontam Borba e Penteado (2016).

Neste sentido, os autores alertam que o professor deve estar em constante aprendizado, pois "por mais que o professor seja experiente é sempre possível que uma nova combinação de teclas e comandos leve a uma situação nova que, por vezes, requer um tempo mais longo para análise e compreensão" (p. 57). O professor precisa saber e estar disposto a enfrentar situações imprevisíveis.

Porém a imprevisibilidade pode ser considerada favorável quando usada da maneira correta.

Aspectos como incerteza e imprevisibilidade, geradas num ambiente informatizado, podem ser vistos como possibilidades para desenvolvimento: desenvolvimento do aluno, desenvolvimento do professor, desenvolvimento das situações de ensino e aprendizagem (BORBA; PENTEADO, 2016, p. 64).

Partindo desse conceito de interação entre os benefícios da informática para a profissionalização de professores bem como para o processo de ensino e aprendizagem dos alunos, Lopes (2013) diz que o 
computador não é apenas uma máquina que transmite informações, mas sim uma ferramenta que propicia a reflexão sobre os resultados obtidos por meio da busca de novos conteúdos e novas estratégias. Segundo a autora, ao usar a tecnologia, a construção do conhecimento acontece no momento em que o aluno busca novos conteúdos e estratégias para acrescentar ao conhecimento que ele possui, de forma que ele consiga resolver o que está sendo estudado via computador. Desse modo o aluno usa o computador para testar, construir, calcular e analisar suas conjecturas, de forma rápida e interativa.

\subsection{O software GeoGebra e o ensino de trigonometria}

Segundo o Instituto São Paulo (apud BORBA; SILVA; GADANIDIS, 2016, p. 47), "O GeoGebra é um software de matemática dinâmica gratuito e multiplataforma para todos os níveis de ensino, que combina geometria, álgebra, tabelas, gráficos, estatística e cálculo numa única aplicação [...]”.

Lopes (2013) acredita que o GeoGebra, por ser um software de matemática dinâmica, possibilita a movimentação dos objetos e, com esses movimentos, o aluno pode investigar o que acontece com a sua construção. Para o autor,

[...], uma das principais características de um software de Geometria Dinâmica é a possibilidade de movimentar os objetos na tela sem alterar as propriedades da construção inicial, com isso, tem-se a possibilidade de, numa atividade desenvolvida com os recursos de um software com essas características, se fazer investigações, descobertas, confirmar resultados e fazer simulações, permitindo, inclusive, levantar questões relacionadas com a sua aplicação prática. (LOPES, 2013, p. 635)

Dessa forma, o estudo de funções se vê facilitado, uma vez que pontos podem ser criados e movimentados sobre o gráfico, com os valores das coordenadas alterados a cada movimento, mas mantendo as propriedades das funções.

Lopes (2013, p. 642), em seu estudo, concluiu que “[...] dentre as potencialidades apresentadas pelo software GeoGebra no ensino e na aprendizagem de trigonometria por meio de atividades investigativas estão, principalmente, a construção, o dinamismo, a investigação, visualização e argumentação".

Nesse sentido, podemos afirmar que atividades matemáticas realizadas com softwares de geometria dinâmica, como o GeoGebra, proporcionam a construção de um ambiente de investigação matemática em sala de aula (BORBA; SILVA; GADANIDIS, 2016), pois construir, formular hipóteses, argumentar, conjecturar são algumas das características das atividades investigativas (PONTE; BROCARDO; OLIVEIRA, 2009).

\subsection{Investigação matemática}

Investigar é procurar conhecer o que não se sabe, definem Ponte, Brocardo e Oliveira (2009). Investigar em Matemática, segundo os autores, é buscar descobrir relações entre objetos matemáticos conhecidos ou desconhecidos, procurando identificar as respectivas propriedades. Os autores ainda 
apontam que investigações em Matemática envolvem, naturalmente, conceitos, procedimentos e representações matemáticas, mas o que mais fortemente as caracteriza é a possibilidade de o aluno analisar, testar, argumentar, conjecturar, discutir e socializar seus resultados com seus colegas. Destacam que esta metodologia de ensino tem se tornado uma poderosa forma de construir conhecimento.

"Ao se propor uma atividade de investigação matemática, espera-se que os alunos possam, de uma maneira mais ou menos consistente, utilizar os vários processos que caracterizam a atividade investigativa em Matemática[...]", apontam Ponte, Brocardo e Oliveira (2009), tais como: a exploração e a formulação de questões, a formulação de conjecturas, o teste e a reformulação de conjecturas e, ainda, a justificação de conjecturas e avaliação do trabalho.

Numa aula (ou conjunto de aulas) de trabalho investigativo, distinguem-se, de um modo geral, três etapas fundamentais: "i) introdução da tarefa, em que o professor faz a proposta à turma, oralmente ou por escrito, ii) realização da investigação, individualmente, aos pares, em pequenos grupos ou com toda a turma, e iii) discussão dos resultados, em que os alunos relatam aos colegas o trabalho realizado" (PONTE; BROCARDO; OLIVEIRA, 2009, p. 25).

$\mathrm{Na}$ primeira etapa, o professor deve buscar envolver os alunos no trabalho, propondo-lhes a realização da tarefa, e no final cabe-lhe conduzir a discussão coletiva. Ao longo de todo este processo, deve estimular a comunicação entre os alunos, criar um ambiente de trabalho onde os alunos se sintam à vontade a pensar, a argumentar e a expor as suas ideias sem medo de serem de imediato avaliados negativamente pelos seus colegas ou pelo professor.

Em atividades investigativas, no caso, com o uso do GeoGebra, Ponte, Brocardo e Oliveira (2009, p. 47) afirmam que o professor deve buscar pelo equilíbrio entre dois polos. Por um lado, deve dar aos alunos, "a autonomia que é necessária para não comprometer a sua autoria na investigação e, por outro lado, garantir que o trabalho dos alunos vá fluindo e seja significativo do ponto de vista da disciplina de Matemática". E ainda, em um certo momento, coordenar a socialização dos resultados obtidos, pois é nesse momento que as conjecturas levantadas serão debatidas.

Os autores destacam que, criar, em sala de aula, um ambiente de investigação com tecnologias tende a facilitar a compreensão dos conceitos estudados, uma vez os alunos ficam mais engajados com as atividades propostas e relatam que, "Em numerosas experiências já empreendidas com trabalho investigativo, os alunos têm mostrado realizar aprendizagens de grande alcance e desenvolver um grande entusiasmo pela Matemática" (p. 10).

Portanto, com o intuito de introduzir o estudo das funções trigonométricas seno, cosseno e tangente e algumas propriedades, com uma abordagem didática baseada na investigação matemática e fazendo uso das tecnologias, optamos pelo uso do software de geometria dinâmica GeoGebra como ferramenta de auxílio na elaboração e execução da atividade que será apresentada posteriormente.

\section{DESCRIÇÃO DO MINICURSO}

As atividades foram desenvolvidas nos dias 21 e 22 de fevereiro de 2018 no Instituto Federal de Educação, Ciência e Tecnologia de Minas Gerais (IFMG) - campus Formiga, durante os Cursos de Verão oferecidos pela instituição, e contou com uma carga horária de 8 horas. 
O público alvo da proposta foram os alunos do $2^{\circ}$ ano do Ensino Médio Integrado do campus, e contou com a presença de 17 alunos, sendo 9 do curso Técnico em Administração e 8 do curso Técnico em Eletrotécnica.

Foi aplicado um questionário inicial com a intenção de definir o perfil dos alunos, além de levantar dados sobre seus conhecimentos sobre o software GeoGebra e sobre como consideravam seu nível de conhecimento em informática.

A faixa etária dos alunos participantes está compreendida entre 15 e 17 anos, sendo 7 alunos com 15 anos, 8 com 16 anos e 2 com 17 anos. Destes, 14 frequentaram o Ensino Fundamental em escola pública, 2 em escola particular com bolsa e apenas 1 aluno frequentou o Ensino Fundamental em escola particular sem bolsa.

Todos os alunos afirmaram já conhecer o GeoGebra, alguns por terem participado de outros minicursos ofertados pelos bolsistas do Programa Institucional de Bolsas de Iniciação à Docência (PIBID), que também fizeram o uso do software. Quando indagados sobre o nível de conhecimento em informática, 15, dos 17 alunos participantes, disseram que possuíam apenas o conhecimento "básico" e somente 2 consideraram seu conhecimento como "médio".

O principal objetivo da proposta era estudar as funções trigonométricas seno, cosseno e tangente no que se refere a definição, domínio, conjunto imagem, sinal nos quadrantes, crescimento e decrescimento, representação gráfica no plano cartesiano e período, com uma abordagem didática baseada na investigação matemática e fazendo uso do software GeoGebra.

\subsection{Desenvolvimento da proposta}

Inicialmente, foram revisados os conceitos das razões trigonométricas seno, cosseno e tangente no triângulo retângulo, além da definição da palavra Trigonometria. Em seguida, houve a introdução teórica de conteúdos que seriam importantes para o desenvolvimento das atividades, tais como relações entre graus e radianos, círculo trigonométrico e seus quadrantes.

Logo após, foram expostos um pouco da história do software GeoGebra e a razão da escolha deste, além da explicação de como seriam desenvolvidas as atividades investigativas.

Conforme disposição dos computadores no laboratório de informática, cada aluno trabalhava individualmente em um computador, no entanto, eles poderiam se comunicar um com o outro a fim de discutirem as atividades, pois segundo Moran, Masetto e Behrens (2000, p.143), "A ênfase no processo de aprendizagem exige que se trabalhe com técnicas que incentivem a participação dos alunos, a interação entre eles, o debate, o diálogo, que promovam a produção do conhecimento [...]”.

Após apresentação das etapas das atividades ${ }^{4}$, foi desenvolvida, com os alunos, a construção ${ }^{5}$ da função seno no ciclo trigonométrico e de seu gráfico.

Ao fim da construção, foi entregue, aos alunos, a atividade 1, ou seja, a folha de registros referente ao estudo da função seno. Sobre este registro, Ponte, Brocardo e Oliveira (2009, p. 33) apontam que "É somente quando se dispõem a registrar as suas conjecturas que os alunos se confrontam com a necessidade

\footnotetext{
${ }^{4}$ As atividades propostas foram retiradas e adaptadas de: Ziegler (2015).

${ }^{5}$ Passo a passo da construção disponível em: https://www.GeoGebra.org/m/pyqctaz5
} 
de explicitarem as suas ideias e estabelecerem consensos e um entendimento comum quanto às suas realizações".

\section{Atividade 1}

Analisando a construção feita no GeoGebra, e/ou o gráfico construído na janela 2 e considerando a definição de função seno:

1) Complete: A medida algébrica do segmento $O A$, representado sobre o eixo $Y$, indica o do ângulo $\alpha$.

2) Indique o sinal, em cada quadrante, da função trigonométrica seno.

3) a) Em que quadrantes a função seno é crescente? E decrescente?

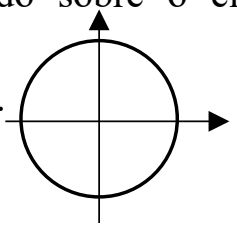

b) Qual o domínio da função seno?

c) Qual o conjunto imagem da função seno?

d) Qual o período da função seno?

Desenvolvida a atividade 1, disponibilizamos, aos alunos, o arquivo do GeoGebra com as construções ${ }^{6}$ prontas para estudo das funções cosseno e tangente para que resolvessem a atividade 2 .

\section{Atividade 2}

Analisando o ciclo trigonométrico da construção do GeoGebra, e/ou os gráficos da janela 2 e considerando as definições de função cosseno e função tangente:

1) Complete as informações abaixo:

a) A medida algébrica do segmento OE, representado sobre o eixo $\mathrm{X}$, indica o do ângulo $\alpha$.

b) A medida algébrica do segmento BG, representado sobre a reta perpendicular ao eixo $\mathrm{X}$, indica a do ângulo $\alpha$.

2) Indique, nos ciclos trigonométricos a seguir, o sinal, em cada quadrante, da função trigonométrica indicada:

a) cosseno

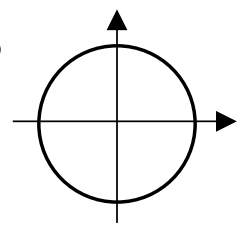

b) tangente

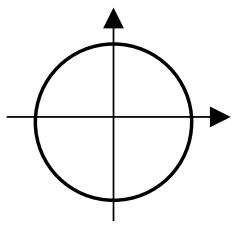

3) a) Em que quadrantes a função cosseno é crescente? E decrescente?

b) Em que quadrantes a função tangente é crescente? E decrescente?

4) a) $\mathrm{O}$ que se observa com os valores da tangente do ângulo $\alpha$ quando o valor de $\alpha$ se aproxima de $90^{\circ}$ ?

b) Qual o domínio das funções cosseno e tangente?

c) Qual o conjunto imagem das funções cosseno e tangente?

d) Qual o período das funções cosseno e tangente?

${ }^{6}$ Disponível em: https://www.GeoGebra.org/m/vkkcctep 
Gravina (1996) destaca que o professor, ao fazer uso de softwares de geometria dinâmica, pode utilizá-los de duas maneiras diferentes: em uma, os próprios alunos fazem a construção das figuras e, neste caso, o objetivo é o domínio dos procedimentos para se obter a construção, enquanto que, numa segunda abordagem, os alunos recebem as figuras prontas.

A atividade 2 foi desenvolvida sem grandes intervenções dos pesquisadores, pois, conforme aponta Freitas (2010, p. 91), “[...] devemos possibilitar ao aluno o máximo de independência para que ele possa desenvolver autenticamente seus próprios mecanismos de resolução do problema [...]”.

No segundo dia de atividades, foram realizadas a discussão e a formalização dos resultados, etapa em que os alunos tiveram a oportunidade de compartilhar com toda a turma o trabalho realizado por eles.

No final de uma investigação, o balanço do trabalho realizado constitui um momento importante de partilha de conhecimentos. Os alunos podem pôr em confronto as suas estratégias, conjecturas e justificações, cabendo ao professor desempenhar o papel de moderador (PONTE; BROCARDO; OLIVEIRA, 2009, p.41).

Neste último momento da atividade, também solicitamos aos alunos que respondessem a um questionário para avaliação das atividades desenvolvidas.

\section{AVALIAÇÃO DA INTERVENÇÃO}

\subsection{Avaliação feita pelos autores da intervenção realizada}

Consideramos que os registros feitos pelos alunos durante a realização da atividade e o momento de socialização das conjecturas nos permitem verificar se o objetivo principal da intervenção - estudar as funções trigonométricas seno, cosseno e tangente no que se refere a definição, domínio, conjunto imagem, sinal nos quadrantes, crescimento e decrescimento, representação gráfica no plano cartesiano e período foi alcançado.

Quanto aos registros feitos durante a atividade, Ponte, Brocardo e Oliveira (2009, p.36) apontam que "[...] a escrita dos resultados ajuda os alunos a clarificarem as suas ideias, nomeadamente a explicitar as suas conjecturas, e favorece o estabelecimento de consensos e de um entendimento comum quanto às suas realizações.

Os registros dos alunos apresentam, em sua maioria, conjecturas corretas. Na atividade 1, que tratava do estudo da função seno, todos os alunos acertaram todas as questões, o que é um indicativo de que compreenderam bem a definição de função seno e as propriedades investigadas. Abaixo, destacamos a resposta do aluno 3 à questão 3 letra $b$ da atividade $I$. 


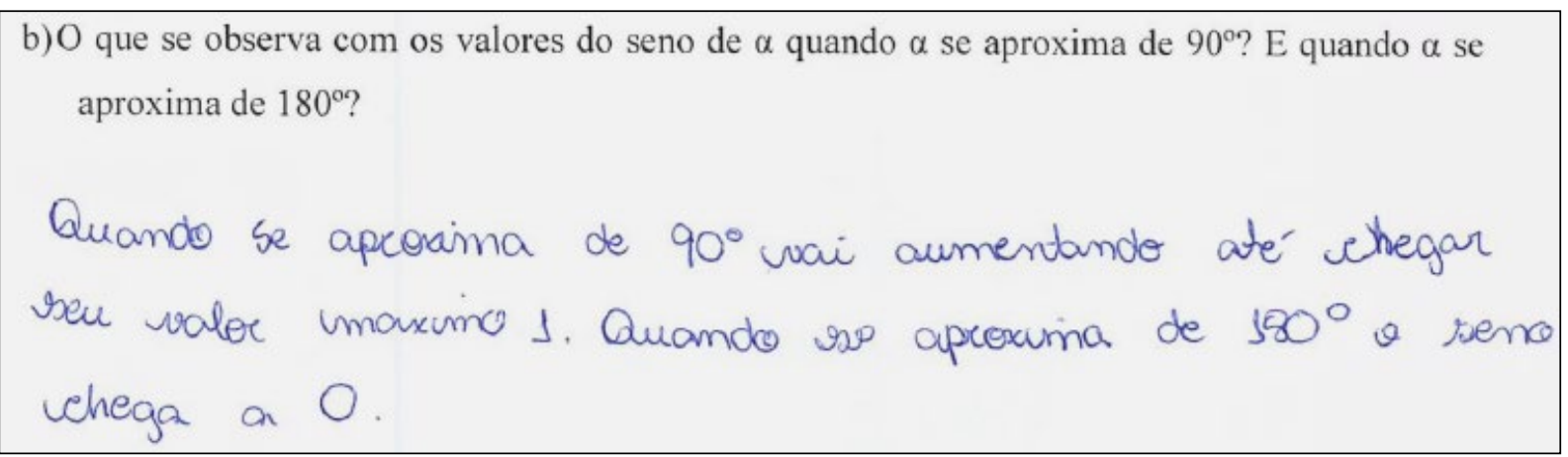

Figura 1: Resposta do aluno 3 à questão 3 letra $b$ da atividade I.

Fonte: Imagem digitalizada pelos autores.

Já na atividade 2, que tratava do estudo das funções cosseno e tangente, todos acertaram as questões 1 e 4, porém alguns apresentaram erros nas demais. Na questão 2 letra a, apenas dois alunos, 11,7\% aproximadamente, apresentaram como sinal da função cosseno, os mesmos que informaram no sinal da função seno. Este erro pode estar ligado a simples repetição das respostas apresentadas na discussão anterior (PEREIRA; GUERRA, 2016), acerca da função seno. Estes mesmos dois alunos, 9 e 10, também erraram a letra $b$, pois responderam que a função tangente possui sinal positivo nos quatro quadrantes.

Já na questão 3 letra a, foram os alunos 4 e 5 que a erraram, apontando o crescimento e decrescimento da função cosseno como sendo o mesmo da função seno. Este erro nos remete, novamente, ao que apontam Pereira e Guerra (2016) sobre a repetição de respostas apresentadas em discussões realizadas anteriormente, ou ainda, à dificuldade de conceitualização de objetos matemáticos em trigonometria (DIONÍZIO; BRANDT, 2011).

Todos acertaram as letras b e c da questão 3. Destacamos, abaixo, as respostas dos alunos 7 e 12 à letra c.

c) O que se observa com os valores do Cosseno e da Tangente quando o valor de $\alpha$ se aproxima de $90^{\circ}$ ?

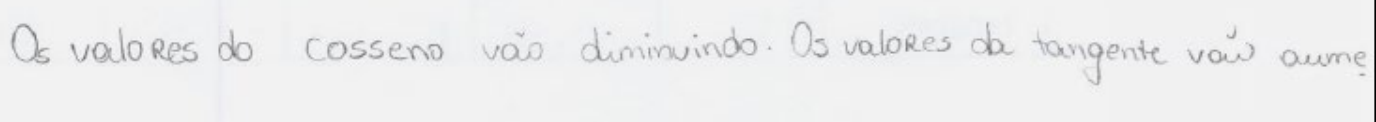

Figura 2: Resposta do aluno 7 à questão 3 letra $b$ da atividade 2

Fonte: Imagem digitalizada pelos autores.

c) O que se observa com os valores do Cosseno e da Tangente quando o valor de $\alpha$ se aproxima de $90^{\circ}$ ?

O) volar do cossem

vingonitio

Figura 3: Resposta do aluno 12 à questão 3 letra $\mathrm{b}$ da atividade 2

Fonte: Imagem digitalizada pelos autores. 
Apesar dos erros detectados em alguns registros, as conjecturas que haviam sido feitas erroneamente pelos alunos 4, 5, 9 e 10 foram corrigidas, durante a socialização, através das discussões, corroborando o que apontam Ponte, Brocado e Oliveira (2009, p. 41) acerca "do balanço do trabalho realizado" constituir-se num momento em que "Os alunos podem pôr em confronto as suas estratégias, conjecturas e justificações, cabendo ao professor desempenhar o papel de moderador".

\subsection{Avaliação feita pelos alunos quanto ao tipo de intervenção realizada}

Após o desenvolvimento das atividades, procuramos identificar o que os discentes acharam da proposta, levando em consideração as respostas apresentadas por eles no questionário de avaliação, aplicado no final das atividades.

Sobre o questionamento 1, "Qual sua opinião em relação à atividade proposta?", a maioria dos alunos afirmaram que foi interessante, que a atividade facilitou a visualização, que foi um jeito prático e divertido de estudar trigonometria, além de terem compreendido o comportamento dos gráficos das funções trigonométricas estudadas. Abaixo, destacamos a opinião de dois alunos sobre a atividade.

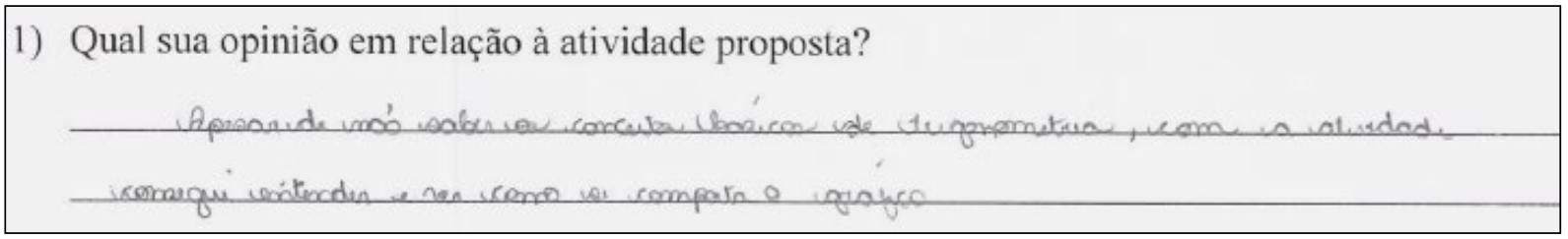

Figura 4: Resposta do aluno 16 à pergunta 1 do questionário de avaliação da atividade Fonte: Imagem digitalizada pelos autores.

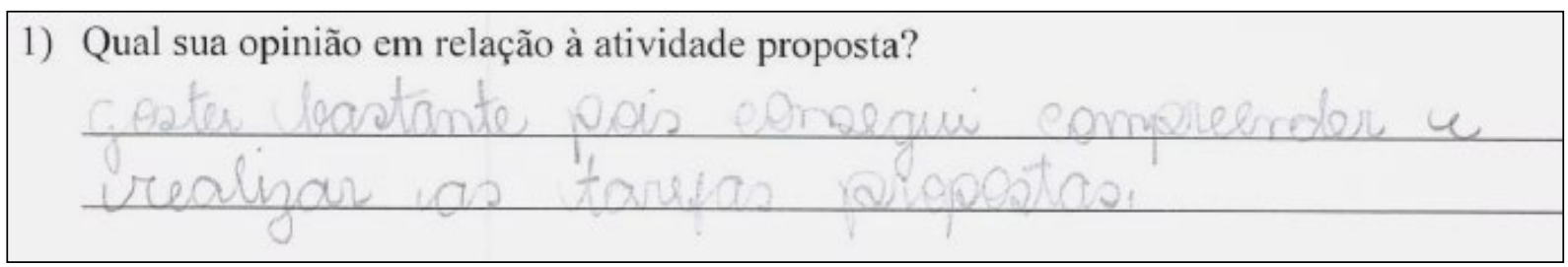

Figura 5: Resposta do aluno 5 à pergunta 1 do questionário de avaliação da atividade Fonte: Imagem digitalizada pelos autores.

Quando questionados se a utilização de softwares durante as aulas pode facilitar a compreensão dos conceitos matemáticos envolvidos nos conteúdos abordados, todos afirmaram que sim, destacando que os softwares os motivam, tornam as explicações mais claras, possibilitando construir e tirar as dúvidas ao mesmo tempo. Também apontaram a possibilidade de compreenderem “... o que é feito para chegar nas conclusões finais". 
2) Em sua opinião, utilizar softwares durante as aulas pode facilitar a compreensão dos conceitos matemáticos envolvidos nos conteúdos abordados? Justifique.

nos eodemen eprestruciur a

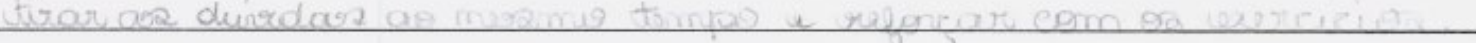

Figura 6: Resposta do aluno 2 à pergunta 2 do questionário de avaliação da atividade Fonte: Imagem digitalizada pelos autores.

2) Em sua opinião, utilizar softwares durante as aulas pode facilitar a compreensão dos conceitos matemáticos envolvidos nos conteúdos abordados? Justifique.

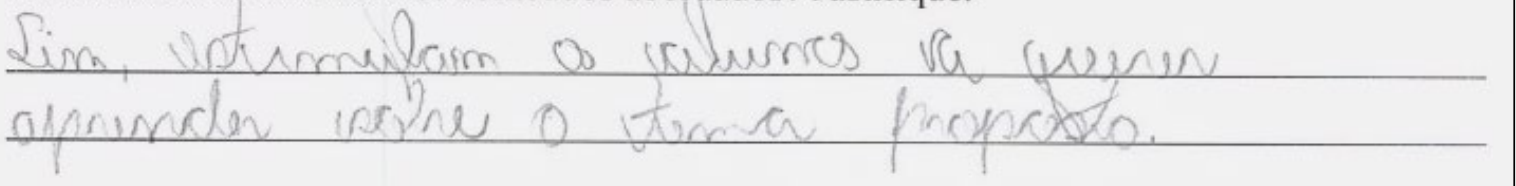

Figura 7: Resposta do aluno 9 à pergunta 2 do questionário de avaliação da atividade Fonte: Imagem digitalizada pelos autores.

2) Em sua opinião, utilizar softwares durante as aulas pode facilitar a compreensão dos conceitos matemáticos envolvidos nos conteúdos abordados? Justifique.

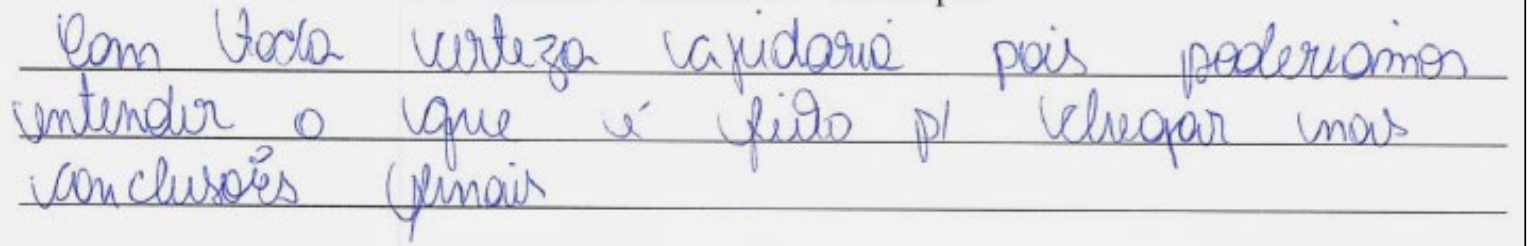

Figura 8: Resposta do aluno 11 à pergunta 2 do questionário de avaliação da atividade

Fonte: Imagem digitalizada pelos autores.

Podemos apontar, nos relatos destacados acima, a motivação ocasionada pelo uso das tecnologias. Santos e Santos (2017, p. 453) acreditam que os professores, ao usarem tecnologias no ensino, tornam "suas aulas mais interessantes e, possivelmente, mais significativas para os alunos".

Identificamos, também, nas respostas apresentadas acima, que as atividades propiciaram um ambiente de investigação com tecnologias (PONTE; BROCARDO; OLIVEIRA, 2009), pois os alunos puderam, através das manipulações feitas no software GeoGebra, investigar o que acontecia com as suas construções (LOPES, 2013) a fim de, como relatou o aluno 11, “... entender o que é feito para chegar nas conclusões finais".

Os alunos também foram indagados sobre o que mais gostaram nas atividades e, dentre as respostas, destacamos as dos alunos 10 e 11, pois estas apontam, respectivamente, para o dinamismo do software GeoGebra e para a possibilidade de os alunos realizarem descobertas por si só, incentivando, desta forma, a compreensão, e dando significado a conceitos matemáticos (LOPES, 2013). 


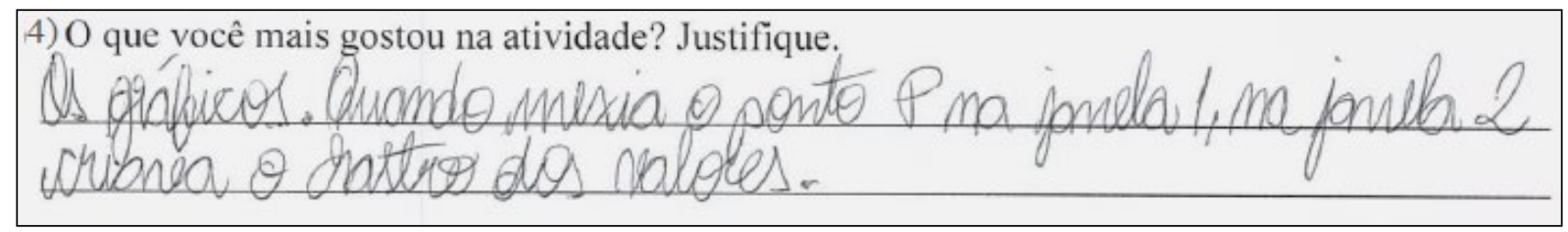

Figura 9: Resposta do aluno 10 à pergunta 3 do questionário de avaliação da atividade Fonte: Imagem digitalizada pelos autores.

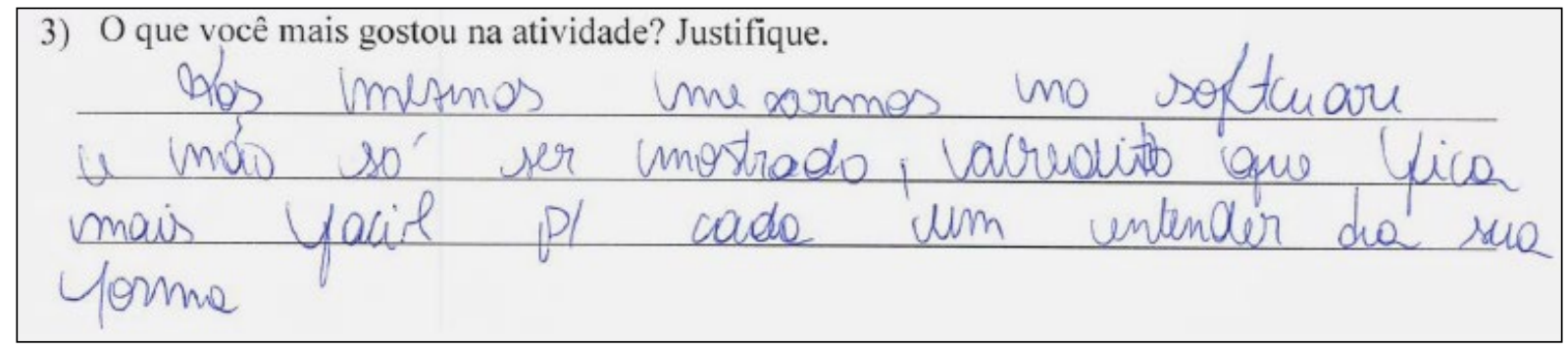

Figura 10: Resposta do aluno 11 à pergunta 3 do questionário de avaliação da atividade Fonte: Imagem digitalizada pelos autores.

Acerca da resposta do aluno 11 (Fig.10), destacamos que este relatou, durante o momento de socialização, que já participou de atividades com uso do GeoGebra, mas apenas com o professor apresentando as construções prontas com uso do data show, ou seja, ele ainda não havia tido a oportunidade de ele mesmo fazer uma construção no software e nem mesmo de manipular uma construção pronta. $\mathrm{O}$ aluno aponta que a atividade o possibilitou fazer descobertas por si só, que lhe foi dado tempo para analisar, pensar, explorar as suas ideias e exprimi-las posteriormente a fim de verificar se "sua forma de entender", ou seja, se suas conclusões estavam ou não corretas.

Por fim, todos os alunos consideraram que seus níveis de conhecimento em informática foram suficientes para o desenvolvimento das atividades. Dentre as justificativas, alguns relataram que acharam fácil o manuseio do software e, mesmo que o GeoGebra possua várias funções, destacaram que as atividades foram realizadas passo a passo.

Enquanto formadora de professores e futuros docentes, acreditamos que a avaliação feita pelos alunos sobre as atividades propostas nos incentiva na inserção das tecnologias nas aulas de Matemática, podendo ser um importante recurso didático.

\section{Considerações Finais}

Consideramos que o desenvolvimento das atividades no software GeoGebra gerou resultados satisfatórios. O objetivo principal - introduzir o estudo das funções trigonométricas seno, cosseno, tangente e algumas propriedades, com uma abordagem didática baseada na investigação matemática e fazendo uso do software GeoGebra - foi alcançado.

Contudo, acreditamos que somente desenvolver as atividades no GeoGebra não seja suficiente. $\mathrm{O}$ momento de socialização e discussão das conjecturas levantadas pelos discentes potencializou a forma 
proposta para estudo das funções trigonométricas seno, cosseno e tangente. Naquele momento, os alunos puderam comparar os resultados obtidos e analisarem suas respostas, estratégias e justificações.

Nesse sentido, também merece destaque a funcionalidade dos registros feitos pelos alunos durante a realização das atividades. O registro trouxe a ligação da atividade no software ao conteúdo na linguagem Matemática para o aluno e, nesse trabalho, foi um instrumento que possibilitou detectar alguns erros. Assim, julgamos ser importante que o professor solicite que os alunos façam registros durante a realização de atividades com o software GeoGebra, assim como em atividades com outros softwares matemáticos.

Acreditamos que o uso do software GeoGebra juntamente com uma abordagem didática baseada na investigação matemática tende a propiciar que o aluno assuma um papel ativo no processo de construção de seu conhecimento, papel esse que julgamos ser fundamental para a aprendizagem.

Por fim, destacamos que a experiência vivenciada propiciou a mobilização de saberes provenientes da formação para o magistério, saberes estes obtidos pela formação e pela socialização nas instituições de formação de professores (TARDIFF, 2008). Estes se revelaram através do planejamento da atividade, da organização do tempo, do uso de recursos didáticos, da organização da turma, entre outros aspectos obtidos no campo da didática durante o curso de formação dos bolsistas, ainda em andamento. Destacamos também a mobilização dos saberes experienciais, os quais, segundo Tardiff (2008), são os saberes que resultam do próprio exercício da atividade profissional dos professores e são produzidos pelos docentes por meio da vivência de situações específicas relacionadas ao espaço da escola e às relações estabelecidas com alunos e colegas de profissão. Os bolsistas do PIBID, futuros docentes, tiveram a oportunidade de vivenciar sua primeira regência e contar com a experiência da docente orientadora e professora supervisora do Programa no planejamento e execução da atividade proposta.

\section{Referências}

BORBA, M. C.; SILVA, R. S. R. da; GADANIDIS, G. Fases das tecnologias digitais em

Educação Matemática: Sala de aula e internet em movimento. 2016. p. 46-48.

BORBA, M. C.; PENTEADO, M. G. Informática e Educação Matemática. 5a ed. 2016.

CARGNIN, C.; FRIZZARINI, S. T. Práticas de Ensino: Novas Tecnologias e Jogos Didáticos. 2. ed. Maringá: Unicesumar, 2018. 156 p.

D’AMBRÓSIO, B. S. Formação de professores de matemática para o século XXI: O grande desafio. Pro-Posições (Unicamp. São Paulo), v. 4, n.1, p. 35-41, mar. 1993. Disponível em: $<$ https://www.fe.unicamp.br/pf-fe/publicacao/1757/10-artigos-ambrosiobs.pdf > . Acesso em: 15 março 2019.

DIONÍZIO, F.Q.; BRANDT, C. F. Análise das dificuldades apresentadas pelos alunos do ensino médio em trigonometria. In: CONGRESSO NACIONAL DE EDUCAÇÃO (EDUCERE), X., 2011, Curitiba. Seminário Internacional de Representações Sociais, Subjetividade e Educação. Anais... 
Curitiba: PUCPR, 2011,14p. Disponível em: <http://educere.bruc.com.br/CD2011/ pdf/4728_2885.pdf >. Acesso em: 26 jan. 2018.

FREITAS, J. L. M. Teoria das situações didáticas. In: MACHADO, S. D. A. (Org.). Educação Matemática: uma (nova) introdução. 3 ed. São Paulo: EDUC, 2010, p. 77-111.

GRAVINA, M. A. Geometria Dinâmica: uma nova abordagem para o aprendizado de geometria. In: SIMPÓSIO BRASILEIRO DE INFORMÁTICA NA EDUCAÇÃO, 7., 1996, Belo Horizonte.

Anais... Belo Horizonte, 1996, 13p. Disponível em:

$<$ http://www.ufrgs.br/espmat/disciplinas/midias_digitais_I/modulo_VIII/artigos.html $>$. Acesso em: 27 jan. 2018.

MAGARINUS, R. Uma proposta para o ensino de funções através da utilização de objetos de aprendizagem. 2013. 99f. (Dissertação de mestrado). Universidade Federal de Santa Maria, Santa Maria, 2013. Disponível em: $<$ http://ufsmprofmat.weebly.com/ uploads/9/3/5/6/9356672/dissertao_renata_magarinus.pdf $>$. Acesso em: 8 fev. 2018.

MORAN, J. M.; MASETTO, M. T.; BEHRENS, M.A. Novas tecnologias e mediação pedagógica. 13. Ed. Campinas: Papirus, 2000.

PEREIRA, E.; GUERRA, E. A. A utilização de applets no GeoGebra para a aprendizagem da trigonometria no ensino médio. Revista de Educação de Ciências e Matemática, v. 7, n. 3, p.5372, 2016. Disponível em:

$<$ http://revistapos.cruzeirodosul.edu.br/index.php/rencima/article/view/1073/828>. Acesso em: 13 maio 2018.

PONTE, J. P. da; BROCARDO, J.; OLIVEIRA, H. Investigações matemáticas na sala de aula. $2^{\mathrm{a}}$ ed. 2009.

LOPES, M. M. Sequência didática para o ensino de trigonometria usando o software GeoGebra. Boletim de Educação Matemática, v. 27, n. 46, 2013.

SANTOS, J. M. A.; SANTOS, J. B. Importância dos softwares educativos no Ensino-aprendizagem da matemática: Uma breve discussão. In: ENCONTRO DE EDUCAÇÃO MATEMÁTICA DE OURO PRETO. ENCONTRO DE ENSINO E PESQUISA EM EDUCAÇÃO MATEMÁTICA. VI. VIII, 2017, Ouro Preto. Anais... Ouro Preto: Editora UFOP, 2017. p. 449-461.

TARDIF, M. Saberes docentes e formação profissional. 9. ed. Petrópolis, RJ: Vozes, 2008. 
ZIEGLER, J. R. et al. Atividades de trigonometria a partir da construção do ciclo

trigonométrico no GeoGebra. Produto Educacional do Programa de Pós-Graduação em Ensino de Ciências Exatas, UNIVATES, Lajeado, 2015. Disponível em:

$<$ https://www.univates.br/ppgece/media/pdf/2015/atividades_de_trigonometria_a_partir_da_constru cao_do_ciclo_trigonometrico_no_GeoGebra.pdf>. Acesso em: 23 jan. 2019.

Recebido em 31/03/2019

Aceito em 25/06/2019 